8-1-2001

\title{
X-ray Photoelectron Spectroscopy (XPS) and Magnetization Studies of Iron-Vanadium Phosphate Glasses
}

\author{
M. A. Salim \\ King Fahd University of Petroleum and Minerals \\ G. D. Khattak \\ King Fahd University of Petroleum and Minerals \\ Petru S. Fodor \\ Cleveland State University, p.fodor@csuohio.edu \\ Follow this and additional works at: https://engagedscholarship.csuohio.edu/sciphysics_facpub \\ 'rwell E. Wenger

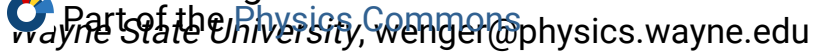 \\ How does access to this work benefit you? Let us know!
}

\section{Publisher's Statement}

NOTICE: this is the author's version of a work that was accepted for publication in Journal of Non-Crystalline Solids. Changes resulting from the publishing process, such as peer review, editing, corrections, structural formatting, and other quality control mechanisms may not be reflected in this document. Changes may have been made to this work since it was submitted for publication. A definitive version was subsequently published in Journal of Non-Crystalline Solids, 289, 1-3, August 2001] DOI\#10.1016/S0022-3093(01)00727-X

\section{Repository Citation}

Salim, M. A.; Khattak, G. D.; Fodor, Petru S.; and Wenger, Lowell E., "X-ray Photoelectron Spectroscopy (XPS) and Magnetization Studies of Iron-Vanadium Phosphate Glasses" (2001). Physics Faculty Publications. 209.

https://engagedscholarship.csuohio.edu/sciphysics_facpub/209

This Article is brought to you for free and open access by the Physics Department at EngagedScholarship@CSU. It has been accepted for inclusion in Physics Faculty Publications by an authorized administrator of EngagedScholarship@CSU. For more information, please contact library.es@csuohio.edu. 


\title{
X-ray photoelectron spectroscopy (XPS) and magnetization studies of iron vanadium phosphate glasses
}

\author{
M.A. Salim , G.D. Khattak , P.S. Fodor , L.E. Wenger
}

\section{Introduction}

Studies of semiconducting oxide glasses containing mixed transition-metal (TM) oxides have been pursued in part because of the detection of mixed exchange pairs in these glasses [1 11]. For example, Bogomolova et al. $[5,6]$ have shown that a strong exchange interaction exists between $\mathrm{Cu}^{2+}$ and $\mathrm{V}^{4+}$ ions in the $\mathrm{BaO}-\mathrm{V}_{2} \mathrm{O}_{5}-\mathrm{CuO}$ and $\mathrm{P}_{2} \mathrm{O}_{5}-\mathrm{CaO}-\mathrm{V}_{2} \mathrm{O}_{5}-\mathrm{CuO}$ glass systems, which leads to the formation of mixed exchange $\mathrm{Cu}^{2+}-\mathrm{V}^{4+}$ pairs. The formation of these mixed clusters also appears to affect the electrical properties of these vanadate and vanadium phosphate glasses as electron hopping between the different TM ions can occur. Furthermore, the inclusion of the TM magnetic species in oxide glasses provides an opportunity to study these exchange pair formations through the interactions between the magnetic 
ions. Electron paramagnetic resonance, magnetic susceptibility and Mössbauer spectroscopy have been particularly successful in studying the mixed exchange pair formation $\mathrm{Cu}^{2+}-\mathrm{V}^{4+}$ and $\mathrm{Cu}^{2+}-\mathrm{Mn}^{4+}$ in the $\mathrm{B}_{2} \mathrm{O}_{3}-\mathrm{K}_{2} \mathrm{O}$ glass system $\left[\begin{array}{ll}8 & 10\end{array}\right]$ and of $\mathrm{Fe}^{3+}-\mathrm{V}^{4+}$ in the $\mathrm{BaO}-\mathrm{V}_{2} \mathrm{O}_{5}$ glass system [7].

In order to provide additional information on the interactions between unlike magnetic ions in vitreous matrices, magnetic susceptibility $(\chi)$ measurements in combination with X-ray photoelectron spectroscopy (XPS) and inductively coupled plasma spectroscopy (ICP) have been used to determine the ratio of different valence states of the $\mathrm{V}$ and $\mathrm{Fe}$ ions in vanadium phosphate glasses containing $\mathrm{Fe}_{2} \mathrm{O}_{3}$. In these $\mathrm{V}_{2} \mathrm{O}_{5}-\mathrm{P}_{2} \mathrm{O}_{5}$ glasses, $\mathrm{V}_{2} \mathrm{O}_{5}$ is partially replaced by $\mathrm{Fe}_{2} \mathrm{O}_{3}$ and the possibility exists for magnetic interactions between the conjugate ions $\mathrm{V}^{4+}\left(3 \mathrm{~d}^{1}\right)$ and $\mathrm{Fe}^{3+}\left(3 \mathrm{~d}^{5}\right)$ or $\mathrm{Fe}^{2+}$ $\left(3 d^{6}\right)$. The extent and nature of this interaction can correspondingly be deduced from parameters associated with the observed Curie Weiss behavior $(\chi=C /(T-\theta))$ of these glasses.

\section{Experimental procedure}

\section{Glass preparation}

The glasses were prepared by melting dry mixtures of reagent grade $\mathrm{V}_{2} \mathrm{O}_{5}, \mathrm{P}_{2} \mathrm{O}_{5}$ and $\mathrm{Fe}_{2} \mathrm{O}_{3}$ in alumina crucibles with the batch composition $\left[\left(\mathrm{Fe}_{2} \mathrm{O}_{3}\right)_{x}\left(\mathrm{~V}_{2} \mathrm{O}_{5}\right)_{0.6-x}\left(\mathrm{P}_{2} \mathrm{O}_{5}\right)_{0.4}\right]$, where $x=0.00$, $0.10,0.20,0.25$ and 0.30 . Since the oxidation and reduction reactions in a glass melt are known to depend on the size of the melt, on the sample geometry, on whether the melt is static or stirred, on thermal history and on quenching rate, all glass samples were prepared under similar conditions to minimize these factors [12]. Approximately $30 \mathrm{~g}$ of chemicals were thoroughly mixed to obtain homogenized batches. The crucible containing the batch mixture was placed in a furnace, heated at $300^{\circ} \mathrm{C}$ for $1 \mathrm{~h}$ and then transferred to an electrically heated melting furnace maintained at $1100^{\circ} \mathrm{C}$. The melt was left for about $3.5 \mathrm{~h}$ under atmospheric conditions in the furnace during which the melt was occasionally stirred with an alumina rod. The homogenized melt was then cast onto a stainless steel plate mold to form glass buttons and glass rods of approximately $5 \mathrm{~mm}$ diameter for XPS measurements. The batch and actual compositions of the glasses studied are listed in Table 1 with the actual compositions determined by ICP spectroscopy.

\section{Magnetization measurements}

The temperature-dependent dc magnetic susceptibility was measured using a Quantum Design SQUID magnetometer in a magnetic field of 100.0 Oe over a temperature range $5300 \mathrm{~K}$. The susceptibility of the sample holder is negligible below $100 \mathrm{~K}$ for all samples and less than a $2 \%$ correction at the highest temperature for samples with a total susceptibility less than $1 \times 10^{-8} \mathrm{emu} / \mathrm{Oe}$. The overall accuracy of the magnetic measurements is estimated to be approximately $3 \%$ due to the uncertainty of the magnetometer calibration.

\section{$X$-ray photoelectron spectroscopy (XPS)}

High-resolution photoelectron spectra were collected on a spectrometer equipped with dual

Table 1

Batch and actual composition (molar fraction) of various vanadium phosphate glasses containing $\mathrm{Fe}_{2} \mathrm{O}_{3}$

\begin{tabular}{|c|c|c|c|c|c|c|}
\hline & \multicolumn{3}{|l|}{ Batch } & \multicolumn{3}{|c|}{ Actual (from ICP) } \\
\hline & $\mathrm{P}_{2} \mathrm{O}_{5}$ & $\mathrm{~V}_{2} \mathrm{O}_{5}$ & $\mathrm{Fe}_{2} \mathrm{O}_{3}$ & $\mathrm{P}_{2} \mathrm{O}_{5}$ & $\mathrm{~V}_{2} \mathrm{O}_{5}$ & $\mathrm{Fe}_{2} \mathrm{O}_{3}$ \\
\hline & 0.40 & 0.60 & 0.00 & 0.398 & 0.602 & 0.000 \\
\hline & 0.40 & 0.50 & 0.10 & 0.401 & 0.502 & 0.097 \\
\hline & 0.40 & 0.40 & 0.20 & 0.407 & 0.402 & 0.191 \\
\hline & 0.40 & 0.35 & 0.25 & 0.401 & 0.349 & 0.250 \\
\hline$[\mathrm{A}]$ & 0.40 & 0.30 & 0.30 & 0.421 & 0.301 & 0.279 \\
\hline [B] & 0.40 & 0.30 & 0.30 & 0.398 & 0.294 & 0.309 \\
\hline
\end{tabular}


aluminum magnesium anodes using $\mathrm{A} 1 \mathrm{~K} \alpha$ radiation $(h v=1486.6 \mathrm{eV})$ as described elsewhere [13]. The electron analyzer was set at a bandpass energy of $20 \mathrm{eV}$ with the energy scale of the spectrometer calibrated using the core level of $\mathrm{Cu} 2 \mathrm{p}_{3 / 2}(932.4$ $\mathrm{eV})$ and the energy separation between $\mathrm{Cu} 2 \mathrm{p}_{3 / 2}$ and $\mathrm{Cu} 2 \mathrm{p}_{1 / 2}(19.8 \mathrm{eV})$. The charging of nonconducting glass samples was avoided by flooding the sample with a separate source of low-energy electrons. The energy and intensity of these external electrons were adjusted to obtain the best resolution as judged by the narrowing of the fullwidth at half-maximum (FWHM) of the photoelectron peaks. At the optimum settings of the neutralizing gun (electron kinetic energy between 5 and $10 \mathrm{eV}$ and electron emission current at the sample between 1 and $5 \mathrm{nA}$ ), the position of the adventitious $\mathrm{C} 1 \mathrm{~s}$ line was within $\pm 0.5 \mathrm{eV}$ of 284.6 $\mathrm{eV}$. This peak arises due to hydrocarbon contamination and its binding energy is generally accepted as remaining constant, irrespective of the chemical state of the sample. For the sake of consistency, all energies are reported with respect to the $\mathrm{C} 1 \mathrm{~s}$ transition at $284.6 \mathrm{eV}$. Glass rods of approximately $5 \mathrm{~mm}$ diameter were broken by vacuum cleavage inside the preparation chamber of the spectrometer in order to obtain fresh glass surface. The typical time required to collect an XPS spectrum for a sample was about $4 \mathrm{~h}$ and the base pressure in the analysis chamber during these measurements was less than $5 \times 10^{-11}$ mbar.

\section{Results}

A typical, low-resolution X-ray photoelectron spectrum for a $\mathrm{Fe}_{2} \mathrm{O}_{3}$ vanadium phosphate glass sample $(x=0.20)$ is shown in Fig. 1. This widescan spectrum as well as similar spectra obtained for the other glass compositions was obtained in about $1 \mathrm{~h}$ using non-monochromatic $\mathrm{Al} \mathrm{K} \alpha$. In addition to the photoelectrons and Auger transitions of the glass constituents, the $\mathrm{C} 1 \mathrm{~s}$ transition is evident at $284.6 \mathrm{eV}$. Since this peak is associated with the hydrocarbon contamination and almost always present on samples introduced from the laboratory environment or from a glove box [14], it is used as an energy reference. The resulting peak

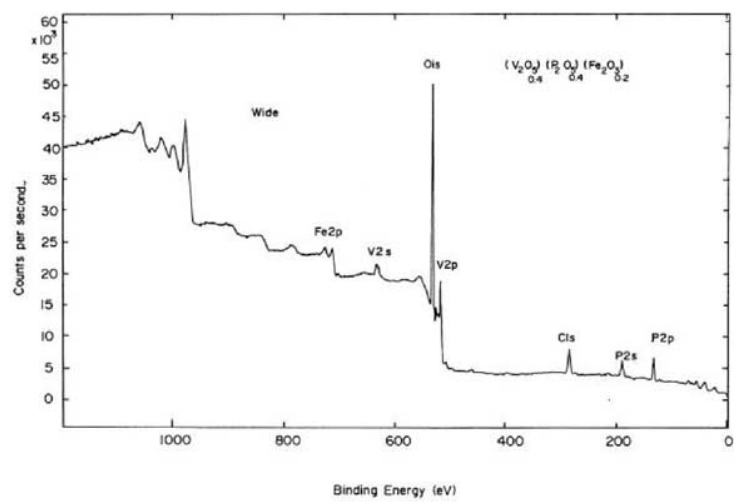

Fig. 1. A low-resolution XPS spectrum from a fractured surface of a $\mathrm{Fe}_{2} \mathrm{O}_{3}$ vanadium phosphate glass with $x=0.2$ obtained using $\mathrm{Al} \mathrm{K} \alpha$ radiation $(h v=1486.6 \mathrm{eV})$.

positions for the Fe 2p, V 2p, P 2p, P 2s and O 1s core levels based on this assignment are listed in Table 2.

Fig. 2 compares the high-resolution $\mathrm{V} 2 \mathrm{p}$ and $\mathrm{O}$ 1s core level spectra for these $\mathrm{Fe}_{2} \mathrm{O}_{3}$ vanadium phosphate glasses with the spectra of $\mathrm{V}_{2} \mathrm{O}_{5}$ and $\mathrm{P}_{2} \mathrm{O}_{5}$ powders. While it is apparent that $\mathrm{V} 2 \mathrm{p}_{3 / 2}$ and $2 \mathrm{p}_{1 / 2}$ peak positions for the glass samples are essentially the same as that for the $\mathrm{V}_{2} \mathrm{O}_{5}$ powder, the V $2 \mathrm{p}$ spectra for the glasses are significantly broader and more asymmetric at the lower energies. Such broadening of the V $2 p$ spectra suggests the existence of some non-equivalent vanadium atoms. Since vanadium can exist in several different valence states [15], each $\mathrm{V} 2 \mathrm{p}_{3 / 2}$ spectrum was decomposed into two Lorentzian Gaussian peaks with a linear slopping background by means of a least-square fitting program [16] as shown in Fig. 3. The resulting peak positions and the relative areas under the peaks determined from this fitting for each spectra are given in Table 3 . The difference between the positions of the two peaks $\left(\Delta \mathrm{V} 2 \mathrm{p}_{3 / 2}\right)$ is about $1.1 \mathrm{eV}$, which is in agreement with the reported difference between the binding energies of $\mathrm{V}^{5+}$ (in $\mathrm{V}_{2} \mathrm{O}_{5}$ ) and $\mathrm{V}^{4+}$ (in $\mathrm{VO}_{2}$ ) [17]. In general, $\mathrm{V}^{5+}$ compounds have higher binding energies than vanadium compounds having $\mathrm{V}$ ions in a lower oxidation state. Thus the lower binding energy and the higher binding energy peaks are assigned to $\mathrm{V}^{4+}$ and $\mathrm{V}^{5+}$, respectively, with the relative areas under the peaks representing the relative ratio of $\mathrm{V}^{4+}$ and $\mathrm{V}^{5+}$ being present. 
Table 2

Peak positions (in eV) for the core levels Fe 2p, V 2p, P 2p, P 2s and O 1s relative to the C 1s peak (284.6 eV) and the FWHM for the O 1s level

\begin{tabular}{|c|c|c|c|c|c|c|c|c|}
\hline$x$ & $\mathrm{Fe} 2 \mathrm{p}_{3 / 2}$ & $\mathrm{Fe} 2 \mathrm{p}_{1 / 2}$ & $\mathrm{~V} 2 \mathrm{p}_{3 / 2}$ & $\mathrm{~V} 2 \mathrm{p}_{1 / 2}$ & P $2 p$ & $\mathrm{P} 2 \mathrm{~s}$ & $\mathrm{O} 1 \mathrm{~s}$ & FWHM (O 1s) \\
\hline 0.00 & & & 517.16 & 524.56 & 133.61 & 190.95 & 530.91 & 1.70 \\
\hline 0.10 & 712.06 & 725.41 & 517.17 & 524.56 & 133.58 & 191.03 & 531.19 & 3.03 \\
\hline 0.20 & 711.77 & 725.37 & 517.25 & 524.72 & 133.56 & 191.02 & 531.18 & 2.38 \\
\hline 0.25 & 711.65 & 725.25 & 517.32 & 524.67 & 133.32 & 190.98 & 531.17 & 2.12 \\
\hline 0.30 & 712.08 & 725.49 & 517.51 & 524.76 & 133.46 & 191.03 & 531.40 & 2.10 \\
\hline \multirow[t]{2}{*}{$\mathrm{P}_{2} \mathrm{O}_{5}$} & & & & & 135.37 & 192.87 & [d] 531.88 & $2.06(0.397)$ \\
\hline & & & & & & & [b] 533.59 & $2.22(0.603)$ \\
\hline $\mathrm{V}_{2} \mathrm{O}_{5}$ & & & 517.38 & 524.88 & & & 530.32 & \\
\hline $\mathrm{Fe}_{2} \mathrm{O}_{3}$ & 710.80 & 724.18 & & & & & & \\
\hline
\end{tabular}

The uncertainty in the peak positions is $\pm 0.10 \mathrm{eV}$ and in FWHM is $\pm 0.20 \mathrm{eV}$. The two $\mathrm{O} 1 \mathrm{~s}$ peaks for $\mathrm{P}_{2} \mathrm{O}_{5}$ represent the doublebonded oxygen sites [d] and the bridging oxygen sites [b] with the numbers in parentheses representing the relative areas under each peak.

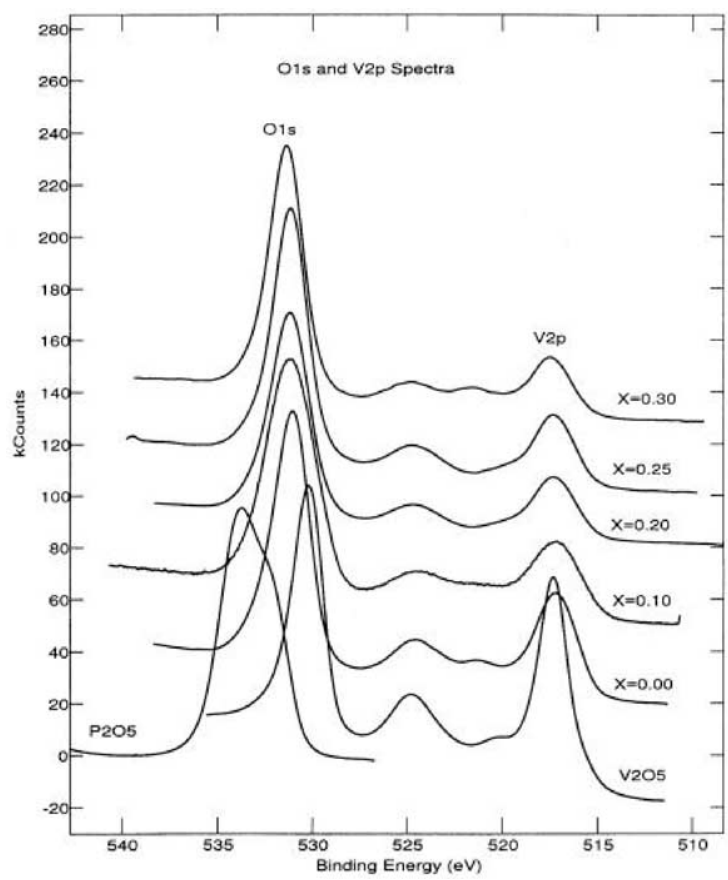

Fig. 2. High-resolution $\mathrm{O} 1 \mathrm{~s}$ and $\mathrm{V} 2 \mathrm{p}$ spectra for the $\mathrm{Fe}_{2} \mathrm{O}_{3}$ vanadium phosphate glasses, $\mathrm{V}_{2} \mathrm{O}_{5}$ and $\mathrm{P}_{2} \mathrm{O}_{5}$ powders.

It is also evident in Fig. 2 that the $\mathrm{O} 1 \mathrm{~s}$ peak for $\mathrm{P}_{2} \mathrm{O}_{5}$ is very asymmetric and, in fact, consists of two overlapping peaks. It is well known that orthorhombic $\mathrm{P}_{2} \mathrm{O}_{5}$ is based on an assembly of discrete molecules consisting of four $\mathrm{PO}_{4}$ tetrahedra with three oxygen atoms being shared by the three

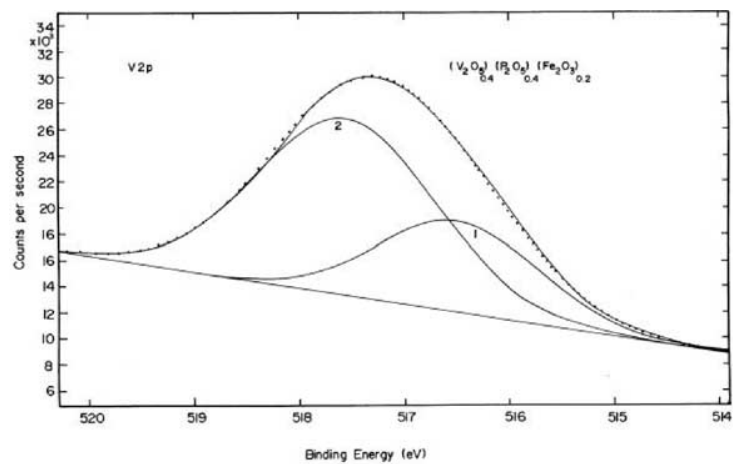

Fig. 3. A high-resolution $\mathrm{V} 2 \mathrm{p}_{3 / 2}$ spectrum (points) for a $\mathrm{Fe}_{2} \mathrm{O}_{3}$ vanadium phosphate glass $(x=0.2)$ and the resulting peaks from a least-squares fitting routine (solid lines).

neighboring tetrahedra and the other being double-bonded to the phosphorus atom [18]. From charge density considerations, the non-bridging atom peak will be shifted towards a lower binding energy with respect to the bridging oxygen atom peak [19]. Thus after decomposing the $\mathrm{O} 1 \mathrm{~s}$ spectra into two peaks, the lower binding peak at $531.9 \mathrm{eV}$ is associated with the non-bridging oxygen $(\mathrm{P}=\mathrm{O}$ bonds) and the higher energy peak at $533.6 \mathrm{eV}$ is associated with the bridging oxygen ( $\mathrm{P}-\mathrm{O}-\mathrm{P}$ bonds) for the $\mathrm{P}_{2} \mathrm{O}_{5}$ powder. In addition, the ratio of the areas under the $\mathrm{P}=\mathrm{O}$ and $\mathrm{P}-\mathrm{O}-\mathrm{P}$ peaks should reflect the relative ratio of $2: 3$ for nonbridging oxygen atoms to bridging oxygen atom for every $\mathrm{P}_{2} \mathrm{O}_{5}$ molecule. The resulting determi- 
Table 3

The peak positions (in $\mathrm{eV}$ ) resulting from the curve fitting of the $\mathrm{V} 2 \mathrm{p}_{3 / 2}$ and $\mathrm{Fe} 2 \mathrm{p}_{3 / 2}$ peaks for the various glass samples

\begin{tabular}{lll}
\hline$x$ & $\mathrm{~V} 2 \mathrm{p}_{3 / 2}$ & $\mathrm{Fe} 2 \mathrm{p}_{3 / 2}$ \\
\hline 0.00 & $516.1(0.165)$ & \\
& $517.3(0.835)$ & \\
0.10 & $516.6(0.518)$ & $711.9(0.634)$ \\
& $517.8(0.482)$ & $714.2(0.366)$ \\
0.20 & $516.7(0.439)$ & $711.8(0.541)$ \\
& $517.7(0.561)$ & $713.3(0.459)$ \\
0.25 & $516.7(0.415)$ & $711.7(0.564)$ \\
& $517.7(0.585)$ & $713.9(0.436)$ \\
0.30 & $516.8(0.398)$ & $711.6(0.524)$ \\
& $517.9(0.602)$ & $714.0(0.476)$ \\
\hline
\end{tabular}

The relative areas under each peak are in parentheses. The uncertainty in the peak positions is $\pm 0.1 \mathrm{eV}$.

nation of the relative areas as shown in Table 2 is in agreement with this prediction.

In comparison to the $\mathrm{P}_{2} \mathrm{O}_{5}$ powder spectrum, the spectra for the vanadium phosphate glass samples and the $\mathrm{V}_{2} \mathrm{O}_{5}$ powder are much more symmetric without any discernible evidence for more than a single peak. Furthermore, the FWHM of the $\mathrm{O}$ 1s spectra for the glasses are comparable to the FWHM deduced from fitting either of the two $\mathrm{O} 1 \mathrm{~s}$ peaks for the $\mathrm{P}_{2} \mathrm{O}_{5}$ powder as shown in Table 2. Thus the data suggest that a 'single' type of oxygen bond dominates the local oxygen structure in the vanadium phosphate glasses even though the $\mathrm{O} 1 \mathrm{~s}$ spectra for the glasses are broader than that for the $\mathrm{V}_{2} \mathrm{O}_{5}$ powder.

Fig. 4 shows the high-resolution Fe $2 p$ spectra for the glass samples as well as the spectrum for $\mathrm{Fe}_{2} \mathrm{O}_{3}$ powder. Although the $\mathrm{Fe} 2 \mathrm{p}_{3 / 2}$ and $2 \mathrm{p}_{1 / 2}$ peak positions for the glass samples are approximately $1.2 \mathrm{eV}$ higher in energy than that for the $\mathrm{Fe}_{2} \mathrm{O}_{3}$ powder, the binding energies are in good agreement with those reported for iron phosphate glasses [20]. Furthermore, since $\mathrm{Fe}$ can exist in either the $\mathrm{Fe}^{2+}$ or $\mathrm{Fe}^{3+}$ state, the $\mathrm{Fe} 2 \mathrm{p}_{3 / 2}$ peaks for the glass samples are also decomposed into two separate peaks as shown in Fig. 5. From this fitting routine, two peaks with average values of 711.7 and $713.8 \mathrm{eV}$ are found (see Table 3) and are assigned to $\mathrm{Fe}^{2+}$ and $\mathrm{Fe}^{3+}$, respectively. This assignment is based on the binding energy of

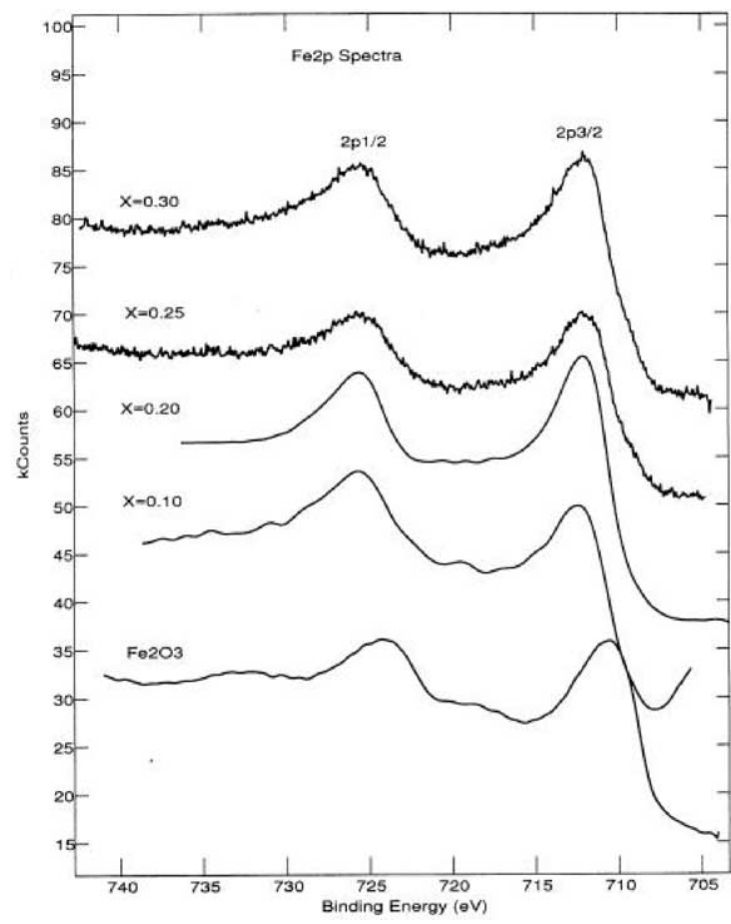

Fig. 4. High-resolution $\mathrm{Fe} 2 \mathrm{p}_{3 / 2}$ spectra for the $\mathrm{Fe}_{2} \mathrm{O}_{3}$ vanadium phosphate glasses and $\mathrm{Fe}_{2} \mathrm{O}_{3}$ powder.

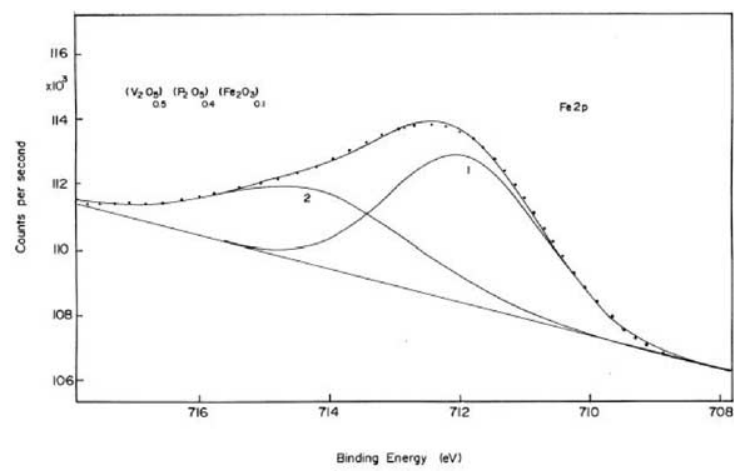

Fig. 5. A high-resolution $\mathrm{Fe} 2 \mathrm{p}_{3 / 2}$ spectrum (points) for a $\mathrm{Fe}_{2} \mathrm{O}_{3}$ vanadium phosphate glass $(x=0.1)$ and the resulting peaks from a least-squares fitting routine (solid lines).

$\mathrm{Fe}(\mathrm{III})_{2} \mathrm{O}_{3}$ being about $12 \mathrm{eV}$ higher than that for $\mathrm{Fe}(\mathrm{II}) \mathrm{O}[21]$ and the strong agreement with the $\mathrm{Fe}$ $2 \mathrm{p}_{3 / 2}$ peak positions reported for $\mathrm{Fe}^{2+}$ and $\mathrm{Fe}^{3+}$ in the iron phosphate glasses [20]. The fitting routine further suggests that the ratio of the relative $\mathrm{Fe}^{3+}$ 
to $\mathrm{Fe}^{2+}$ areas increases with increasing iron content in these $\mathrm{Fe}_{2} \mathrm{O}_{3}$ vanadium phosphate glasses.

The variation in the binding energies of the $\mathrm{P} 2 \mathrm{p}$ and $\mathrm{P} 2 \mathrm{~s}$ electrons has also been examined. Figs. 6 and 7 compare high-resolution XPS spectra of the $\mathrm{P} 2 \mathrm{p}$ and $\mathrm{P} 2 \mathrm{~s}$ core levels for the glasses to that of $\mathrm{P}_{2} \mathrm{O}_{5}$ powder. Each spectrum appears to consist of a single peak whose width remains essentially unchanged; however, both the P $2 p$ and P 2 s peaks for the glasses shift by about $1.9 \mathrm{eV}$ to lower energies as shown in Table 2. Also it should be noted that the binding energies of the $\mathrm{P} 2 \mathrm{p}$ and $\mathrm{P} 2 \mathrm{~s}$ electrons for all glass samples is essentially independent of the Fe content.

The magnetic susceptibility results for the glasses are shown in Figs. 8 and 9 as plots of inverse mass magnetic susceptibility, $\chi^{-1}$, as a function of the temperature, $T$. The data appear to follow a Curie Weiss behavior $(\chi=C /(T-\theta))$ over most of the temperature range. From the slope and intercept, the Curie constant, $C_{\text {expt }}$ and paramagnetic Curie temperature, $\theta(\mathrm{K})$, are de-

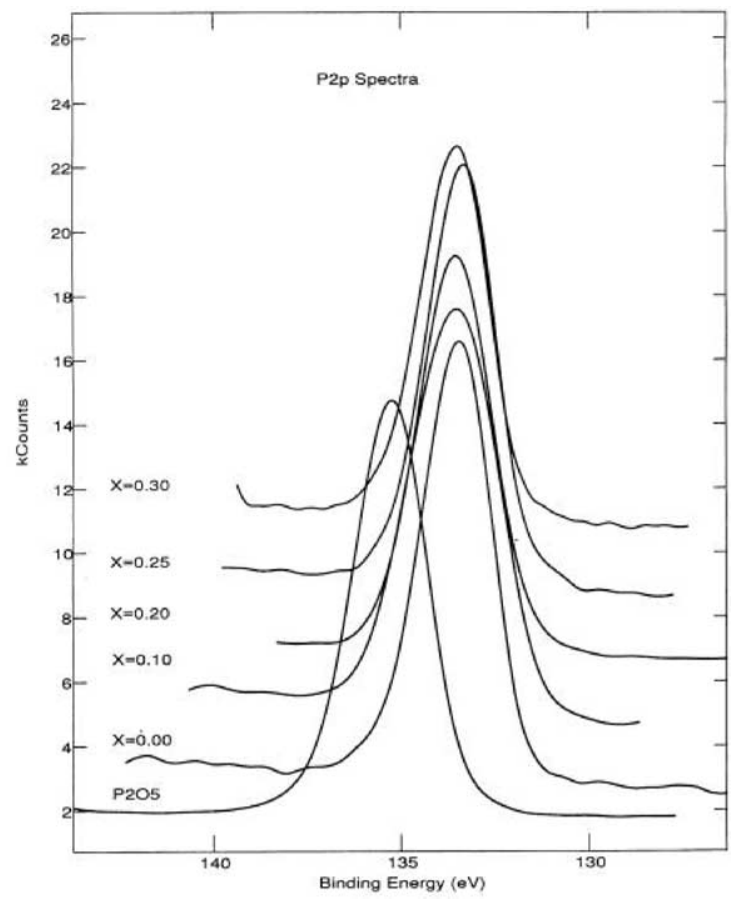

Fig. 6. High-resolution $\mathrm{P} 2 \mathrm{p}$ spectra for the $\mathrm{Fe}_{2} \mathrm{O}_{3}$ vanadium phosphate glasses and $\mathrm{P}_{2} \mathrm{O}_{5}$ powder.

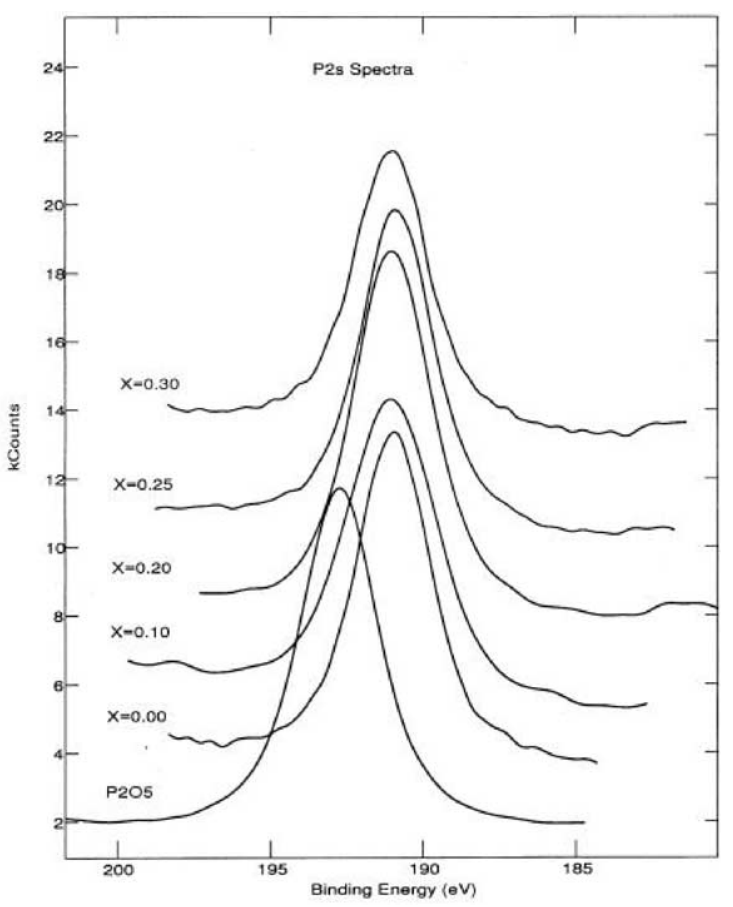

Fig. 7. High-resolution $\mathrm{P} 2 \mathrm{~s}$ spectra for the $\mathrm{Fe}_{2} \mathrm{O}_{3}$ vanadium phosphate glasses and $\mathrm{P}_{2} \mathrm{O}_{5}$ powder.

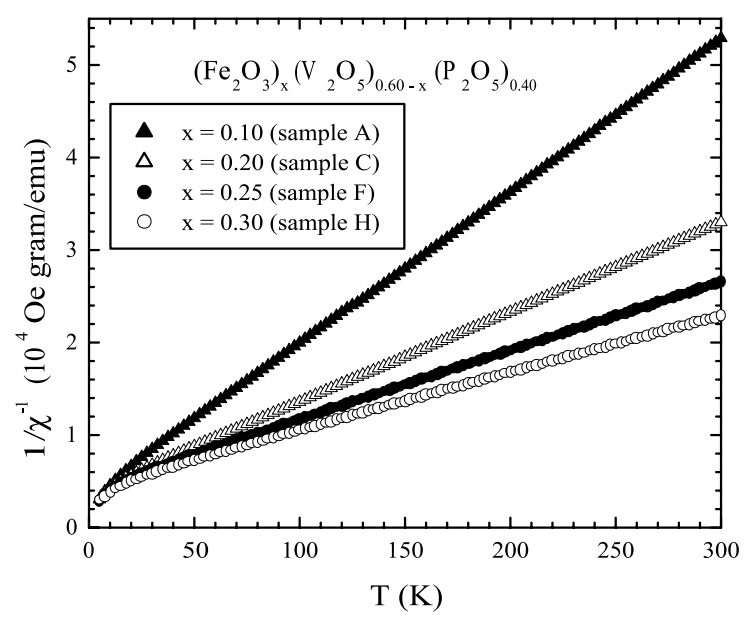

Fig. 8. The inverse of mass magnetic susceptibility as a function of temperature for the $\mathrm{Fe}_{2} \mathrm{O}_{3}$ vanadium phosphate glasses in a magnetic field of $100 \mathrm{Oe}$.

termined for each of the glass samples (see Table 4). Both the Curie constants and the magnitudes of the paramagnetic Curie temperature increase with 


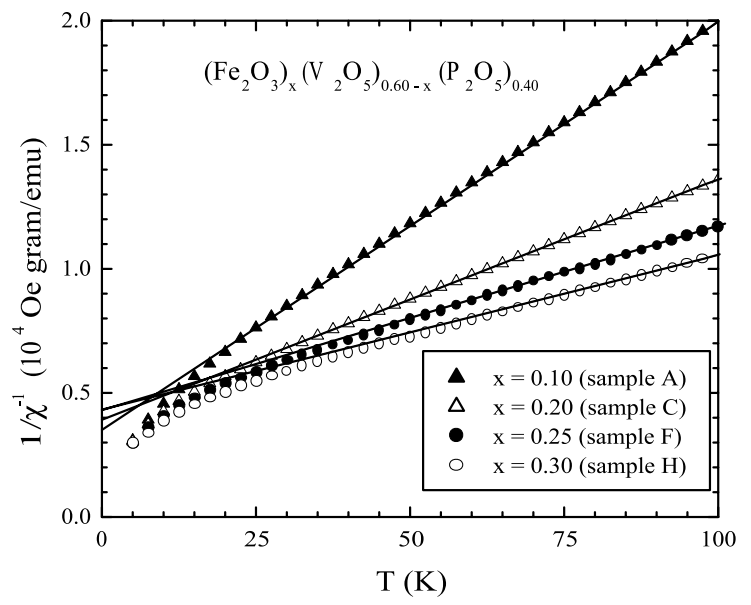

Fig. 9. The inverse of mass magnetic susceptibility as a function of temperature for the $\mathrm{Fe}_{2} \mathrm{O}_{3}$ vanadium phosphate glasses for temperatures below $100 \mathrm{~K}$. The solid lines represent Curie Weiss fits to the high-temperature data.

increasing $\mathrm{Fe}$ content in the glasses. Since the paramagnetic Curie temperature, $\theta$, is a rough measure of the strength of the interaction between the magnetic ions in the sample, a higher value implies stronger interaction and/or more ions participating in the interaction. The negative values for the paramagnetic Curie temperatures in- dicate that the magnetic interaction is predominately antiferromagnetic in these $\mathrm{Fe}_{2} \mathrm{O}_{3}$ vanadium phosphate glasses.

\section{Discussion}

As described in the preceding section, XPS provides information of the short-range structure in these glasses. For example, the $\mathrm{O} 1 \mathrm{~s}$ spectrum for $\mathrm{P}_{2} \mathrm{O}_{5}$ in Fig. 2 was found to consist of two overlapping peaks centered at 533.6 and $531.9 \mathrm{eV}$ with a ratio of relative areas of nearly $3: 2$. This is understood in terms of the higher binding energy being associated with the six bridging oxygen atoms ( $\mathrm{P}-\mathrm{O}-\mathrm{P}$ type of bonds) in the $\mathrm{P}_{4} \mathrm{O}_{10}$ structure and the lower binding energy with the four doublebonded oxygen atoms ( $\mathrm{P}=\mathrm{O}$ bonds). Following similar arguments for a difference in the binding energies between bridging and non-bridging oxygen sites, the spectrum for $\mathrm{V}_{2} \mathrm{O}_{5}$ powder should have two peaks as four of the oxygen atoms in the $\mathrm{V}_{2} \mathrm{O}_{5}$ crystal structure are double-bonded oxygen ( $\mathrm{V}=\mathrm{O}$ bonds) while only one is a bridging oxygen ( $\mathrm{V}-\mathrm{O}-\mathrm{V}$ bond). The narrowness and symmetry of the $\mathrm{O}$ 1s peak for $\mathrm{V}_{2} \mathrm{O}_{5}$ powder suggest that the energy difference between $\mathrm{V}=\mathrm{O}$ and $\mathrm{V}-\mathrm{O}-\mathrm{V}$ bonds

Table 4

Magnetic susceptibility results for the vanadium phosphate glass samples and comparison to calculated paramagnetic Curie constants based on ICP and XPS results to experimental results

\begin{tabular}{|c|c|c|c|c|c|c|c|c|}
\hline & \multicolumn{3}{|c|}{ Molar fraction (nominal) } & \multirow{2}{*}{$\begin{array}{l}C_{\text {expt }} \\
(\mathrm{emu} \mathrm{K} / \mathrm{g} \mathrm{Oe})\end{array}$} & \multirow{2}{*}{$\begin{array}{l}\theta_{\text {expt }} \\
(\mathrm{K})\end{array}$} & & & \\
\hline & $\mathrm{Fe}_{2} \mathrm{O}_{3}$ & $\mathrm{~V}_{2} \mathrm{O}_{5}$ & $\mathrm{P}_{2} \mathrm{O}_{5}$ & & & & & \\
\hline \multirow{14}{*}{$\begin{array}{l}{[\mathrm{A}]} \\
{[\mathrm{B}]}\end{array}$} & 0.00 & 0.60 & 0.40 & $7.35 \times 10^{-4}$ & -0.97 & & & \\
\hline & 0.10 & 0.50 & 0.40 & $6.09 \times 10^{-3}$ & -21.4 & & & \\
\hline & 0.20 & 0.40 & 0.40 & $1.03 \times 10^{-2}$ & -40.4 & & & \\
\hline & 0.25 & 0.35 & 0.40 & $1.35 \times 10^{-2}$ & -57.9 & & & \\
\hline & 0.30 & 0.30 & 0.40 & $1.53 \times 10^{-2}$ & -63.7 & & & \\
\hline & 0.30 & 0.30 & 0.40 & $1.61 \times 10^{-2}$ & -69.5 & & & \\
\hline & \multicolumn{3}{|c|}{ Molar fraction (from ICP) } & \multicolumn{2}{|c|}{ Ion fraction (from XPS) } & MW & $C_{\text {calc }}$ & $C_{\text {expt }}$ \\
\hline & $\mathrm{Fe}_{2} \mathrm{O}_{3}$ & $\mathrm{~V}_{2} \mathrm{O}_{5}$ & $\mathrm{P}_{2} \mathrm{O}_{5}$ & $\mathrm{Fe}^{3+} / \mathrm{Fe}_{\text {total }}$ & $\mathrm{V}^{5+} / \mathrm{V}_{\text {total }}$ & $(\mathrm{g} / \mathrm{mol})$ & $(\mathrm{emu} \mathrm{K} / \mathrm{g} \mathrm{Oe})$ & $(\mathrm{emu} \mathrm{K} / \mathrm{g} \mathrm{Oe})$ \\
\hline & 0.000 & 0.602 & 0.398 & 0.000 & 0.766 & 163.591 & $6.97 \times 10^{-4}$ & $7.35 \times 10^{-4}$ \\
\hline & 0.097 & 0.502 & 0.401 & 0.366 & 0.482 & 158.570 & $6.10 \times 10^{-3}$ & $6.09 \times 10^{-3}$ \\
\hline & 0.191 & 0.402 & 0.407 & 0.459 & 0.561 & 156.912 & $1.06 \times 10^{-2}$ & $1.03 \times 10^{-2}$ \\
\hline & 0.250 & 0.349 & 0.401 & 0.436 & 0.585 & 155.746 & $1.34 \times 10^{-2}$ & $1.35 \times 10^{-2}$ \\
\hline & 0.279 & 0.302 & 0.421 & 0.476 & 0.602 & 154.979 & $1.50 \times 10^{-2}$ & $1.53 \times 10^{-2}$ \\
\hline & 0.309 & 0.294 & 0.398 & 0.476 & 0.602 & 154.849 & $1.65 \times 10^{-2}$ & $1.61 \times 10^{-2}$ \\
\hline
\end{tabular}


may be too small to be observed, especially since the relative weight of the two types of bonds is $4: 1$. Similarly, no discernible second peak is observed in the $\mathrm{O} 1 \mathrm{~s}$ spectrum for the Fe-free vanadium phosphate $\left[\left(\mathrm{V}_{2} \mathrm{O}_{5}\right)_{0.6}\left(\mathrm{P}_{2} \mathrm{O}_{5}\right)_{0.4}\right]$ glass sample, even though it is broader than that for $\mathrm{V}_{2} \mathrm{O}_{5}$. Assuming that the local structure at this vanadium concentration maintains the $\mathrm{P}_{4} \mathrm{O}_{10}$ structure, then the following types of bonds should exist with the corresponding relative weightings:

$\mathrm{P}=\mathrm{O} \quad 4\left(1-n_{\mathrm{v}}\right)=1.60$, where $n_{\mathrm{v}}=0.60$,

P-O-P $\quad 8\left(1-n_{\mathrm{v}}\right)^{2}-2\left(1-n_{\mathrm{v}}\right)=0.48$,

$\mathrm{P}-\mathrm{O}-\mathrm{V} \quad 16 n_{\mathrm{v}}\left(1-n_{\mathrm{v}}\right)=3.84$,

$\mathrm{V}-\mathrm{O}-\mathrm{V} \quad 8\left(n_{\mathrm{v}}\right)^{2}-2\left(n_{\mathrm{v}}\right)=1.68$,

$\mathrm{V}=\mathrm{O} \quad 4 n_{\mathrm{v}}=2.40$.

Thus less than $5 \%$ of the total number of possible oxygen bonds should be bridging oxygen bonds $(\mathrm{P}-\mathrm{O}-\mathrm{P})$ in this highly concentrated vanadium phosphate glass and the remaining $95 \%$ should be non-bridging oxygen atoms $(\mathrm{P}=\mathrm{O}, \quad \mathrm{P}-\mathrm{O}-\mathrm{V}$, $\mathrm{V}-\mathrm{O}-\mathrm{V}$ and $\mathrm{V}=\mathrm{O}$ ) whose photoelectrons would give rise to the observed single $O$ 1s peak. In principle, this $\mathrm{O} 1 \mathrm{~s}$ peak could be decomposed into four smaller peaks representing each of these four types of non-bridging oxygen atoms; however, it would require a minimum of eight fitting parameters. Furthermore, the separation of the peaks might be indistinguishable as a previous XPS study on alkali phosphate glasses [22] showed that contributions in the $\mathrm{O} 1 \mathrm{~s}$ spectra from the doublebonded oxygen atoms $(\mathrm{P}=\mathrm{O})$ and the 'non-bridging' oxygen atoms (P O Na) had an energy difference on the order of $0.1 \mathrm{eV}$ or less. Thus, it is doubtful that any meaningful insight into the local structure would be gained from a four-peak fitting analysis, especially considering the narrowness of the observed $\mathrm{O} 1 \mathrm{~s}$ peak. Instead, it is more reasonable to hypothesize that all of the non-bridging oxygen atoms have nearly the same binding energies. The addition of $\mathrm{Fe}_{2} \mathrm{O}_{3}$ into the vanadium phosphate glass structure will result in nonbridging $\mathrm{Fe} \mathrm{O} \mathrm{P}$ and $\mathrm{Fe} \mathrm{O} \mathrm{V}$ bonds being formed and replacing some of the non-bridging $\mathrm{P}$ $\mathrm{O} \mathrm{V}, \mathrm{V} \mathrm{O} \mathrm{V}$ and $\mathrm{V}=\mathrm{O}$ bonds with little effect on the relative ratio of the $\mathrm{P} O \mathrm{P}$ bonds to non- bridging oxygen bonds. Thus a single $\mathrm{O}$ 1s peak should remain with minimal shift in the peak position (binding energy of the photoelectrons) as a function of increasing $\mathrm{Fe}_{2} \mathrm{O}_{3}$ concentration.

The $1.9 \mathrm{eV}$ shifts to lower binding energies of the $\mathrm{P} 2 \mathrm{p}$ and $\mathrm{P} 2 \mathrm{~s}$ electrons for the vanadium phosphate glasses are mainly due to a difference in the molecular environment surrounding the $\mathrm{P}$ atom between the $\mathrm{P}_{2} \mathrm{O}_{5}$ and $\mathrm{Fe}$ vanadium phosphate glass structures. While the next-nearest neighbors in $\mathrm{P}_{2} \mathrm{O}_{5}$ are all $\mathrm{P}$ atoms, there is a more than $50 \%$ probability that a $\mathrm{V}$ (or $\mathrm{Fe}$ ) atom will be the next-nearest neighbor in these highly concentrated phosphate glasses. Since the electronegativities of $\mathrm{V}$ and $\mathrm{Fe}$ are lower than that of $\mathrm{P}$ $(=2.1), \mathrm{V}$ and $\mathrm{Fe}$ have less of an affinity for electrons than $\mathrm{P}$. Thus the electron density at the $\mathrm{P}$ atom increases with the the presence of $\mathrm{V} / \mathrm{Fe}$ atoms and leads to a decrease in $\mathrm{P} 2 \mathrm{p}$ and $\mathrm{P} 2 \mathrm{~s}$ binding energies in these glasses. Furthermore, since the ratio of the $\mathrm{V} / \mathrm{Fe}(\sim 0.60)$ to $\mathrm{P}(\sim 0.40)$ remains nearly constant for all glass samples, the $\mathrm{P}$ $2 p$ and $P 2$ s binding energies should show little variation with $\mathrm{Fe}$ content as observed in the XPS spectra.

In comparing binding energies of the $2 \mathrm{p}_{3 / 2}$ and $2 \mathrm{p}_{1 / 2}$ electrons of $\mathrm{V}$ and $\mathrm{Fe}$ in the phosphate glasses to standard TM oxide powders (see Table 2 ), the V $2 p$ peaks for the glass samples and metal oxides are almost at the same positions while the Fe $2 p$ peaks for the glass samples shift by approximately $1.2 \mathrm{eV}$ towards higher binding energies. These shifts can result not only from a change in the molecular environment from $\mathrm{V}_{2} \mathrm{O}_{5}$ and $\mathrm{Fe}_{2} \mathrm{O}_{3}$, but also from a reduction of the formal oxidation state of $\mathrm{V}$ and $\mathrm{Fe}$ in the glass structures [23]. Following a similar explanation to that given in the preceding paragraph, $\mathrm{V}$ and $\mathrm{Fe}$ atoms in the glass structures will be surrounded by a large number of $\mathrm{P}$ atoms instead of $\mathrm{V}$ or $\mathrm{Fe}$ atoms at the next-nearest neighbor positions. Thus the electron density of the $\mathrm{V}$ or $\mathrm{Fe}$ atoms would be smaller while their $2 p$ binding energies would be greater. In contrast, binding energies typically decrease with a reduction in the oxidation state of a metal atom, e.g., $\mathrm{V}^{5+} \rightarrow \mathrm{V}^{4+}$ and $\mathrm{Fe}^{3+} \rightarrow \mathrm{Fe}^{2+}$. Consequently the change in the molecular environment must be the dominant mechanism responsible for 
the shifts in the Fe $2 p$ energies and for keeping the $\mathrm{V} 2 \mathrm{p}$ levels unchanged.

Ideally, magnetic susceptibility measurements should be able to provide an independent verification of the presence and amount of the various magnetic ions in these vanadium phosphate glass samples. However, the presence of three different magnetic ions, i.e., $\mathrm{V}^{4+}\left(p_{\text {eff }}=1.8 \mu_{\mathrm{B}}\right), \quad \mathrm{Fe}^{3+}$ $\left(p_{\text {eff }}=5.9 \mu_{\mathrm{B}}\right)$ and $\mathrm{Fe}^{2+}\left(p_{\text {eff }}=5.4 \mu_{\mathrm{B}}\right)$, results in an overabundance of independent variables such that the magnetic susceptibility data cannot be further analyzed without additional constraints. By using the ratios of $\mathrm{V}^{4+} / \mathrm{V}_{\text {total }}, \mathrm{Fe}^{3+} / \mathrm{Fe}_{\text {total }}$ and $\mathrm{Fe}^{2+} / \mathrm{Fe}_{\text {total }}$ as determined from the XPS analyses and the molar fraction of each constituent as measured from ICP, a comparison between the expected (calculated) value of the Curie constant (see Appendix A) and the experimentally measured value for each sample can be made. As shown in Table 4, the calculated Curie constants are within $3 \%$ of the experimental values for all vanadium phosphate glass samples containing $\mathrm{Fe}$ $(x>0)$ and within $7 \%$ for the $\mathrm{Fe}_{2} \mathrm{O}_{3}$-free glass sample $(x=0)$. Thus the strong correlation between the calculated and experimental Curie constants confirms the present of the three magnetic ions, $\mathrm{V}^{4+}, \mathrm{Fe}^{3+}$ and $\mathrm{Fe}^{2+}$, in these vanadium phosphate glasses. Furthermore, the fact that the paramagnetic Curie temperatures, $\theta$, for all glass samples are non-zero and negative indicates that there are exchange effects between the magnetic spins with the interaction being antiferromagnetic in nature. This is consistent with previous investigations on similar systems [24,25] reporting that the antiferromagnetic interactions are present in magnetic TM oxide glasses. Assuming that the local structure of the glass is $\mathrm{P}_{4} \mathrm{O}_{10}$, the possibility exists for the cluster formation of dimers (two $\mathrm{P}$ sites being occupied by magnetic ions) and closed-trimers (three sites being occupied by magnetic ions in a closed triangle) with a 'nonbridging' oxygen atom between the magnetic ions. It is well known that such oxygen intermediaries provide an indirect exchange mechanism responsible for the antiferromagnetic ordering in magnetic insulators [26].

The observation of the paramagnetic Curie temperature, $\theta$, becoming more negative with increasing $\mathrm{Fe}_{2} \mathrm{O}_{3}$ content in these glass samples implies that the interaction strength between the magnetic ions becomes greater and/or that more ions are participating in the interaction as $\theta \propto J \cdot z \cdot S$, where $J$ is the interaction strength, $z$ the number of magnetic nearest neighbors and $S$ is the magnetic spin. Assuming a random probability for the magnetic ion substitution in the $\mathrm{P}_{4} \mathrm{O}_{10}$ structure, $17 \%$ of the $\mathrm{P}_{4} \mathrm{O}_{10}$ structures would not have any magnetic ions, $38 \%$ would contain a single magnetic ion, $32 \%$ a dimer, $12 \%$ a closedring trimer, and less $2 \%$ would have all $\mathrm{P}$ sites replaced with magnetic ions for the $x=0.10$ glass sample (see Table 5). With increasing Fe content in the vanadium phosphate glasses, the number of dimers, trimers and 'quads' (all P sites occupied by magnetic ions) would increase while the number of the other two possible cluster configurations would decrease. Thus the average value of $z$ and $S$ would increase with increasing $\mathrm{Fe}_{2} \mathrm{O}_{3}$ content. Additionally, one could expect the exchange overlap and hence the effective interaction strength $J$ to increase if the local $\mathrm{P}_{4} \mathrm{O}_{10}$ structure has any contraction in the lattice spacing between the $\mathrm{P}$

Table 5

Probability distribution of a given magnetic cluster type in the $\mathrm{P}_{4} \mathrm{O}_{10}$ structure

\begin{tabular}{llllllll}
\hline Cluster type & Probability & \multicolumn{2}{l}{ Nominal molar fraction of $\mathrm{Fe}_{2} \mathrm{O}_{3}$} & & \\
\cline { 2 - 7 } & & $x=0.0$ & 0.10 & 0.20 & 0.25 & {$[\mathrm{~A}] 0.30$} & {$[\mathrm{~B}] 0.30$} \\
\hline No magnetic ions & $(1-q)^{4}$ & 0.545 & 0.171 & 0.160 & 0.134 & 0.130 & 0.109 \\
Single & $4 q(1-q)^{3}$ & 0.357 & 0.380 & 0.372 & 0.350 & 0.346 & 0.322 \\
Dimer & $6 q^{2}(1-q)^{2}$ & 0.088 & 0.316 & 0.324 & 0.343 & 0.345 & 0.359 \\
Closed-trimer & $4 q^{3}(1-q)$ & 0.010 & 0.117 & 0.126 & 0.149 & 0.153 & 0.178 \\
'Quad' & $q^{4}$ & 0.000 & 0.016 & 0.018 & 0.024 & 0.025 & 0.033 \\
\hline
\end{tabular}

$q=N_{\mathrm{Fe}}+N_{\mathrm{V}} \mathrm{V}^{4+} / \mathrm{V}_{\text {total }}$ ( = the total molar fraction of magnetic ions) where $N_{\mathrm{Fe}}$ and $N_{\mathrm{V}}$ are the molar fractions of Fe and $\mathrm{V}$ determined from ICP analyses of the glass samples. 
sites with the substitution of more $\mathrm{Fe}$ on the $\mathrm{P}$ sites.

Finally, the deviation from the Curie Weiss behavior below $\sim 15 \mathrm{~K}$ can be explained on the basis of the local $\mathrm{P}_{4} \mathrm{O}_{10}$ structures consisting of single magnetic ions, dimers, etc. In the lowtemperature regime $(T \ll J)$, the magnetic susceptibilities for antiferromagnetic dimers and 'quads' would vanish to zero while that for the trimers would remain finite but small. However, the susceptibility of the non-interacting, single magnetic ions continues to increase as $1 / T$. Consequently, the paramagnetic contribution of these non-interacting magnetic ions to the susceptibility will become the most dominant contribution and cause the downturn observed in the temperature dependence of the inverse susceptibility below $15 \mathrm{~K}$.

\section{Conclusions}

By combining studies of the XPS spectra for $\mathrm{O}$ $1 \mathrm{~s}, \mathrm{P} 2 \mathrm{p}, \mathrm{P} 2 \mathrm{~s}, \mathrm{Fe} 2 \mathrm{p}$ and V $2 \mathrm{p}$ core levels of the $\mathrm{Fe}_{2} \mathrm{O}_{3}$ vanadium phosphate glasses with magnetic susceptibility measurements, the local structure of these glasses and the nature of the interactions between the magnetic ions have been investigated. The $\mathrm{O}$ 1s spectra for the glasses show a single, symmetric peak which results from nearly $95 \%$ of the oxygen sites in the local $\mathrm{P}_{4} \mathrm{O}_{10}$ structure being occupied by non-bridging oxygen atoms. The shifts in the binding energies of the Fe $2 p$ (1.2 eV increase), the V $2 p$ (no change) and both the $\mathrm{P} 2 \mathrm{p}$ and $\mathrm{P} 2 \mathrm{~s}$ (1.9 eV decrease) core levels for these glasses in comparison those for their respective powders $\left(\mathrm{Fe}_{2} \mathrm{O}_{3}, \mathrm{~V}_{2} \mathrm{O}_{3}\right.$ and $\left.\mathrm{P}_{2} \mathrm{O}_{5}\right)$ are explained in terms of changes in their electron densities as a result of differences in the nextnearest neighbor environment between the local structures in the glasses and powders. In addition, the $\mathrm{V} 2 \mathrm{p}_{3 / 2}$ and $\mathrm{Fe} 2 \mathrm{p}_{3 / 2}$ spectra for the glass samples are sufficiently broaden such that two peaks are fitted to the data. These peaks are associated with the presence of $\mathrm{V}^{5+}$ and $\mathrm{V}^{4+}$ and $\mathrm{Fe}^{3+}$ and $\mathrm{Fe}^{2+}$, respectively, and the relative area under each peak reflects the relative amount of each ion. Approximately $40 \%$ of the iron is found to be in the $\mathrm{Fe}^{3+}$ state and $50 \%$ of the vanadium in the $\mathrm{V}^{5+}$ state in the $\mathrm{Fe}_{2} \mathrm{O}_{3}$ vanadium phosphate glass samples. The presence and amount of each of these magnetic ions $\left(\mathrm{V}^{4+}, \mathrm{Fe}^{3+}\right.$ and $\left.\mathrm{Fe}^{2+}\right)$ determined from the XPS results are in quantitative agreement with the analysis from the $\mathrm{Cu}$ rie Weiss behavior $(\chi=C /(T-\theta))$ in the magnetic susceptibility data on the glasses. The Curie constants, $C_{\text {calc }}$, calculated from the XPS and ICP measurements are within $3 \%$ of the experimentally measured values for the Fe-containing vanadium phosphate glasses. The negative paramagnetic Curie temperatures, $\theta$, indicate that the interaction between the magnetic ions is antiferromagnetic in nature. Qualitative features in the magnetic susceptibility results including the deviation from the Curie Weiss behavior below $15 \mathrm{~K}$ and more negative paramagnetic Curie temperatures with increasing Fe content can be satisfactorily explained by considering the formation of magnetic dimers, trimers, etc., with the introduction of the magnetic ions onto the $\mathrm{P}$ sites of the $\mathrm{P}_{4} \mathrm{O}_{10}$ structure. Furthermore, this provides a straightforward explanation for the indirect exchange coupling between $\mathrm{V}^{4+}-\mathrm{Fe}^{3+}, \mathrm{V}^{4+}-\mathrm{Fe}^{2+}$, $\mathrm{Fe}^{3+}-\mathrm{Fe}^{2+}$, etc., that give rise to the antiferromagnetic interactions.

\section{Acknowledgements}

The support of the KFUPM Physics Department and Research Committee and the WSU Institute for Manufacturing Research is greatly acknowledged.

\section{Appendix A}

To calculate the Curie constants from the ratios of $\mathrm{V}^{4+} / \mathrm{V}_{\text {total }}, \mathrm{Fe}^{3+} / \mathrm{Fe}_{\text {total }}$ and $\mathrm{Fe}^{2+} / \mathrm{Fe}_{\text {total }}$ as determined from the XPS results, we will define

$$
\begin{array}{ll}
r=\mathrm{V}^{5+} / \mathrm{V}_{\text {total }} & \text { ratio of number } \mathrm{V}^{5+} \\
& \text { ions to total number of } \\
& \mathrm{V} \text { ions from XPS } \\
& \text { ratio of number } \mathrm{V}^{4+} \\
& \text { ions to total number of } \\
& \text { V ions from XPS }
\end{array}
$$




$$
\begin{aligned}
& r=\mathrm{V}^{5+} / \mathrm{V}_{\text {total }} \\
& (1-r)=\mathrm{V}^{4+} / \mathrm{V}_{\text {total }} \\
& f=\mathrm{Fe}^{3+} / \mathrm{Fe}_{\text {total }} \\
& (1-f)=\mathrm{Fe}^{2+} / \mathrm{Fe}_{\text {total }} \\
& N_{\mathrm{V}} \\
& N_{\mathrm{Fe}} \\
& N_{\mathrm{P}} \\
& C_{\text {calc }}
\end{aligned}
$$

Assuming V only exists either as $\mathrm{V}^{5+}\left(p_{\text {eff }}=0\right)$ or $\mathrm{V}^{4+}\left(p_{\text {eff }}=1.8 \mu_{\mathrm{B}}\right)$ and since $\mathrm{Fe}$ exists as either $\mathrm{Fe}^{3+}\left(p_{\text {eff }}=5.9 \mu_{\mathrm{B}}\right)$ or $\mathrm{Fe}^{2+}\left(p_{\text {eff }}=5.4 \mu_{\mathrm{B}}\right)$, the Curie constant $C_{\text {calc }}$ is given by

$$
\begin{aligned}
C_{\mathrm{calc}}=\{ & f N_{\mathrm{Fe}} \frac{p_{\mathrm{eff}}^{2}\left(\mathrm{Fe}^{3+}\right)}{3 k_{\mathrm{B}}}+(1-f) N_{\mathrm{Fe}} \frac{p_{\mathrm{eff}}^{2}\left(\mathrm{Fe}^{2+}\right)}{3 k_{\mathrm{B}}} \\
& \left.+(1-r) N_{\mathrm{V}} \frac{p_{\mathrm{eff}}^{2}\left(\mathrm{~V}^{4+}\right)}{3 k_{\mathrm{B}}}\right\} \frac{N_{\mathrm{A}}}{\mathrm{MW}}
\end{aligned}
$$

where $N_{\mathrm{A}}$ is Avogadro's number and MW is the molecular weight of the glass sample. The molecular weight is determined from the following expression:

$$
\begin{aligned}
\mathrm{MW}= & f N_{\mathrm{Fe}} M W_{\mathrm{Fe}_{2} \mathrm{O}_{3}}+(1-f) N_{\mathrm{Fe}} M W_{\mathrm{Fe}_{2} \mathrm{O}_{2}} \\
& +r N_{\mathrm{V}} M W_{\mathrm{V}_{2} \mathrm{O}_{5}}+(1-r) N_{\mathrm{V}} M W_{\mathrm{V}_{2} \mathrm{O}_{4}} \\
& +N_{\mathrm{P}} M W_{\mathrm{P}_{2} \mathrm{O}_{5}} .
\end{aligned}
$$

[3] A.K. Bandyopadhyay, J.O. Isard, J. Phys. D 10 (1977) L99.

[4] L.D. Bogomolova, J. Non-Cryst. Solids 30 (1979) 379.

[5] L.D. Bogomolova, M.P. Glassova, J. Non-Cryst. Solids 37 (1980) 423.

[6] L.D. Bogomolova, V.A. Jachkin, M.P. Glassova, S.N. Spasibkina, J. Phys. 42 (1981) C4-993.

[7] L.D. Bogomolova, M.P. Glassova, O.E. Dubatovko, S.I. Reiman, S.N. Spasibkina, J. Non-Cryst. Solids 58 (1983) 71.

[8] O. Cozar, I. Ardelean, Physica 27 (1982) 41.

[9] O. Cozar, I. Ardelean, Gh. Ilonca, Solid State Commun. 44 (1982) 809.

[10] I. Ardelean, O. Cozar, Gh. Ilonca, J. Non-Cryst. Solids 68 (1984) 33.

[11] G.D. Khattak, M.A. Salim, L.E. Wenger, A.H. Gilani, J. Non-Cryst. Solids 262 (2000) 66.

[12] E. Culear, J. Non-Cryst. Solids 223 (1998) 47.

[13] E.E. Khawaja, Z. Hussain, M.S. Jazzar, O.B. Dabbousi, J. Non-Cryst. Solids 93 (1987) 45.

[14] G.E. Mullenberg (Ed.), Handbook of X-ray Photoelectron Spectroscopy, Perkin Elmer, Norwalk, CT, 1970.

[15] C.R. Bamford, Color Generation and Control in Glass, Elsevier, Amsterdam, 1977.

[16] A. Proctor, P.M.A. Sherwood, Anal. Chem. 52 (1980) 2315.

[17] J.F. Moulder, W.F. Stickle, P.E. Sobol, K.D. Bomben, Handbook of X-ray Photoelectron Spectroscopy, Perkin Elmer, Eden Prairie, MN, 1992.

[18] J. Wong, C.A. Angell, Glass Structure by Spectroscopy, Marcel Dekker, New York, 1976.

[19] B.M.J. Smets, D.M. Krol, Phys. Chem. Glasses 25 (1984) 113.

[20] R.K. Brow, C.M. Arens, X. Yu, E. Day, Phys. Chem. Glasses 35 (1994) 132.

[21] C.D. Wagner, W.M. Riggs, L.E. Davis, J.F. Moulder, in: G.E. Mullenberg (Ed.), Handbook of X-ray Photoelectron Spectroscopy, Perkin Elmer, Eden Prairie, MN, 1979.

[22] R. Bruckner, H.-U. Chun, H. Goretzki, M. Sammet, J. Non-Cryst. Solids 42 (1980) 49.

[23] D. Briggs, J.C. Riviere, in: D. Briggs, M.P. Seah (Eds.), Practical Surface Analysis by Auger and X-ray Photoelectron Spectroscopy, Wiley, Chichester, 1988, p. 119.

[24] C.S. Sunandana, K.S. Rao, Phys. Stat. Sol. A 90 (1958) 681.

[25] I.G. Austine, E.J. Garbett, in: P.G. LeComber, J. Mart (Eds.), Electronic and Structural Properties of Amorphous Semiconductors, Academic Press, London, 1973.

[26] K.P. Sinha, N. Kumar (Eds.), Interactions in Magnetically Ordered Solids, Oxford Press, Oxford, 1980.

\section{References}

[1] G.F. Lynch, M. Sayer, J. Phys. C 6 (1973) 3661.

[2] M. Sayer, G.F. Lynch, J. Phys. C 6 (1973) 3774.

Post-print standardized by MSL Academic Endeavors, the imprint of the Michael Schwartz Library at Cleveland State University, 2017. 